\title{
The Underutilization of Primary Care Providers in Treating Opiate Addiction
}

Jennifer Jenkinson

Follow this and additional works at: https://scholarsarchive.byu.edu/studentpub

Part of the Nursing Commons

The College of Nursing showcases some of our best evidence based scholarly papers from graduate students in the Family Nurse Practitioner Program. The papers address relevant clinical problems for advance practice nurses and are based on the best evidence available. Using a systematic approach students critically analyze and synthesize the research studies to determine the strength of the evidence regarding the clinical problem. Based on the findings, recommendations are made for clinical practice. The papers are published in professional journals and presented at professional meetings.

\section{BYU ScholarsArchive Citation}

Jenkinson, Jennifer, "The Underutilization of Primary Care Providers in Treating Opiate Addiction" (2014). Student Works. 8.

https://scholarsarchive.byu.edu/studentpub/8

This Master's Project is brought to you for free and open access by BYU ScholarsArchive. It has been accepted for inclusion in Student Works by an authorized administrator of BYU ScholarsArchive. For more information, please contact scholarsarchive@byu.edu, ellen_amatangelo@byu.edu. 
The Underutilization of Primary Care Providers in Treating Opiate Addiction

\author{
Jennifer Jenkinson \\ A literature review submitted to the faculty of \\ Brigham Young University \\ In partial fulfillment of the requirements for the degree of \\ Master of Science \\ Patricia Ravert, Chair \\ College of Nursing \\ Brigham Young University \\ February, 2012
}

Copyright (C) 2012 Jennifer B. Jenkinson

All Rights Reserved 


\section{Table of Contents}

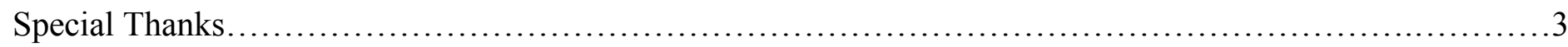

Abstract......................................................................................

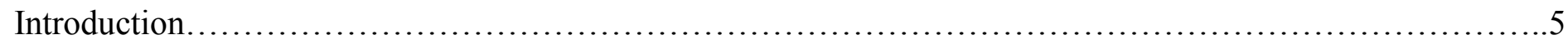

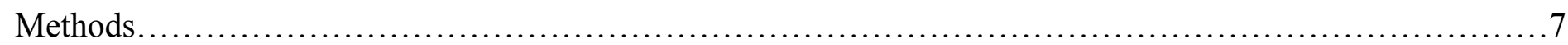

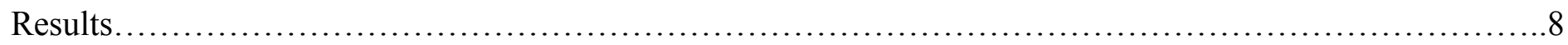

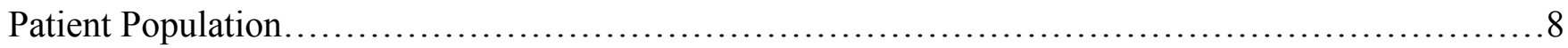

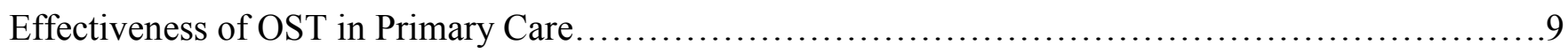

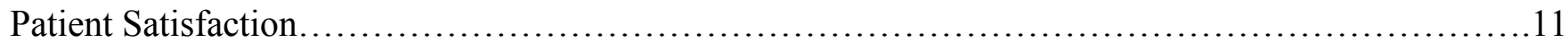

Barriers for OST Treatment in Primary Care................................................. 12

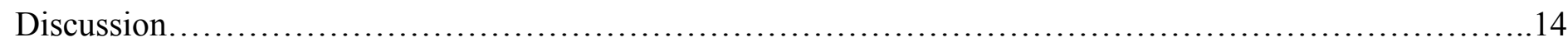

Conclusion...........................................................................

Table 1- Demographics of Patients Entering OST in Primary Care Clinics.................................

Table 2- Perceived Barriers for OST by Physicians................................................

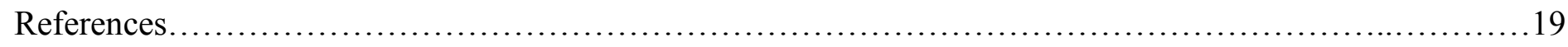




\section{Special Thanks}

I would like to give special thanks to my mentor and co-author Dean Patty Ravert, PhD, RN, CNE, ANEF, FAAN, for all of the positive encouragement and guidance she offered throughout this process. Her knowledge and expertise was invaluable. I would also like to thank Mary Williams PhD, RN; Barbara Mandleco PhD, RN; and Betsy Hopkins for the many hours of teaching the research and writing process.

I would also like to express thanks to: my husband, Charles Jenkinson, who spent countless hours reading, editing, and revising this document; my sister, Cathy Reese, who helped inspire the title of the document; and my children, Anneliese, Gabby, William, and Chris, who were willing to give me time to complete the paper. They have been very patient and understanding while I have been in school. 


\begin{abstract}
Opioid abuse is a worldwide problem and there are not enough care providers or treatment programs available to treat the opioid abuse epidemic. Many primary-care nurse practitioners care for patients who are dependant and/or abuse opioids. Under current legislation, nurse practitioners are not allowed to prescribe the schedule III medications necessary to treat them, even though they have been made available to primary-care physicians with some additional training. This paper discusses the effectiveness of opioid substitution therapy in a primary care setting, the patient population best suited for this therapy, patient satisfaction with primary care service, and the barriers preventing primary care providers from providing treatment to opioid patients. It discusses how nurse practitioners can help overcome some of these barriers and improve access to this underserved population.
\end{abstract}




\section{The Underutilization of Primary Care Providers in Treating Opiate Addiction}

\section{Introduction}

Opioid abuse is a worldwide problem for both industrialized and developing countries.

Specifically, the abuse of prescription opiates is on the rise and is a major public health problem in the United States. ${ }^{1}$ Opioid abuse is defined as using an opiate for a nonmedical purpose or using a prescribed opiate differently (amount, frequency, person prescribed and rational) than it was prescribed by the provider. In 2008, more than 33 million Americans used a pain reliever for a nonmedical purpose. ${ }^{2}$ According to Substance Abuse and Mental Health Data Archive, $13.7 \%$ of Americans reported abusing pain relievers in their lifetime where 1.6\% reported using heroin in 2010. Opioid abuse doubled from 1977-1982, then increased four-fold from 1987-1996. "From 1999-2007, unintentional drug overdose deaths associated with prescription opioids rose by $395 \% .{ }^{4}$ (p355) Opioid abuse is now common with adolescents and the Centers for Disease Control estimates that $\$ 9.5$ billion was spent in 2005 on costs associated with prescription opioid abuse (POA). They estimate that societal costs in 2010 have risen up to more than $\$ 55$ billion. ${ }^{4}$ This places pain reliever abuse just below cocaine abuse, second only to Marijuana. ${ }^{5}$ Primary care providers are frequently faced with this problem as they treat patients.

Historically, opioid addiction has been managed in the U.S. in specialized treatment centers where providers replace the abused opioid with methadone. This has been effective in reducing illicit opioid abuse and retaining patients in treatment. ${ }^{4,6}$ Currently, methadone for opioid addiction can only be prescribed in treatment programs certified by the Federal Substance Abuse and Mental Health Services Administration (SAMHSA). ${ }^{7}$ However, the availability of these treatment centers has failed to meet the increasing demand created by the prescription drug dependence explosion. In 2008 , only $35 \%$ of the 1.7 million opioid-dependent people in the U.S. were in treatment ${ }^{8}$, with a total annual cost of 8.6 billion. ${ }^{9}$ One-third of methadone maintenance clinics 
have lengthy waiting lists and many states do not have any clinics at all, especially in rural areas. ${ }^{2,10,}{ }^{11}$ Studies estimate only $20 \%$ of Americans who suffer from opiate addiction have access to methadone maintenance therapy. ${ }^{2,10}$ Communities often limit these clinics from opening or expanding, and patients often feel stigmatized attending them. ${ }^{2}$ In response the Drug Addiction Treatment Act of 2000 (DATA 2000) was created, which enables qualifying physicians to obtain a waiver allowing them to practice medication-assisted opioid addiction therapy in primary care practice. To qualify, a physician must have a current state medical license, a valid DEA registration number, and complete at least eight hours of training in the treatment and management of opioidaddicted patients or have special addiction certifications. ${ }^{12}$

In 2002, two schedule III controlled medications, Subutex (buprenorphine hydrochloride) and Suboxone (buprenorphine hydrochloride and naloxone hydrochloride), received FDA approval for the treatment of opioid addiction. ${ }^{12}$ There is "extensive empirical evidence" that suggests buprenorphine is safe and effective for treating opioid addiction in a primary care setting, ${ }^{13}$ (p92) and it has a much lower risk of overdose than methadone. Buprenorphine is a mu-receptor agonist and a kappa-receptor antagonist; therefore, it has an opioid effect with no additional effect beyond a certain point (ceiling effect) with increased dosing. It has slow onset of action, high affinity for receptor sites, and attaches tightly to receptors. This gives it a long half-life and patients do not experience sedation or euphoria when taking it. It will replace other opioids at receptors sites triggering withdrawal symptoms in patients who are physically dependent on opioids. As a result, buprenorphine treatment should not be started until the patient begins withdrawal symptoms. When buprenorphine is combined with naloxone, the potential for abuse is decreased further. Naloxone is an opioid antagonist and reverses opioid effects at the mu and kappa-receptor sites. However, it is not absorbed well when ingested orally; therefore, it has no effect when taken sublingually as prescribed. If a person attempts to abuse Suboxone by crushing it and injecting it, the naloxone creates a rapid reversal of the opioid effect. This acts as a natural deterrent to abuse and prevents Suboxone from being used in ways not prescribed or intended.7,14,15 
Despite the adoption of DATA 2000 and buprenorphine therapy, primary care opioid addiction therapy is severely underutilized. There are few physicians with the waiver to prescribe the medications ${ }^{16}$ and half of those are addiction specialists. ${ }^{17}$ Many people would benefit if a wider array of physicians would provide this treatment. ${ }^{17}$ Under the current legislation, nurse practitioners (NPs) and physician assistants (PAs) are prohibited from prescribing these medications, even in the states with controlled substances prescription authority. This further limits the availability of treating a population already suffering from a "treatment gap". ${ }^{18}(\mathrm{p} 144)$

This paper discusses why there is an underutilization of primary care providers in treating opiate addiction, by comprehensively reviewing past research identifying the patient populations best suited for opiate addiction therapy in a primary care setting, the effectiveness of primary care providers in treating opiate addiction, the patient's preferences of treatment centers, and the barriers preventing primary care physicians from practicing opiate addiction therapy in their practices. It will discuss how involving NPs can help overcome these barriers, improve access, cost effectiveness, and reduce the "treatment gap" for people suffering from opiate addiction. $^{18}$

\section{Methods}

An electronic search with terms of opiates or opioid, drug abuse or drug addiction or drug dependency or substance abuse, rehabilitation or treatment or therapy or recovery, and primary care or general practice was conducted in CINAHL, MEDLINE, and PsycINFO databases. The search was limited to peer-reviewed articles published in English from 2006 to April, 2013. Abstracts of 303 articles were reviewed to identify relevant research studies, resulting in eleven on patient populations, four on patient satisfaction, twelve on effectiveness, and six on barriers.

An electronic search with terms of nurse practitioner or physician assistant or advanced practice, prescribe, and buprenorphine was also conducted to identify articles calling for a policy change addressing the 
lack of privileges of NPs to prescribe buprenorphine from 2006 to April, 2013 in CINAHL, MEDLINE, and PsycINFO databases. The search was limited to peer-reviewed articles published in English resulting in five articles.

\section{Results}

The review of literature showed four themes evaluating opioid substitution therapy (OST) in a primary care setting. The themes include the patient populations best suited for primary care, the effectiveness of OST in primary care, patient satisfaction with primary care service, and the barriers preventing primary care providers from providing treatment to opioid dependent patients.

\section{Patient Population}

Eleven studies were identified that researched the types of patients seeking OST at primary care practices. They ranged from 35 to 2,308 subjects. Seven studies were retrospective chart review descriptive designs, three were descriptive studies, and one was a randomized clinical trial. Ten were performed in the United States and the subjects were primarily Caucasian, and five studies had fewer than 100 subjects so generality is limited.

Research shows those seeking office-based buprenorphine treatment is a new type of patient that has not received drug abuse treatment. ${ }^{19}$ Table 1, Demographics of patients entering OST at primary care clinics, summarizes the descriptive characteristics of these studies. The average age of people entering treatment is $36-$ 39 years old, 56-80\% are male, $45-85 \%$ are full-time employed, and $35-75 \%$ have no history of prior methadone maintenance therapy (MMT) or other treatment. On average, they have less than 10 years of opioid dependence and have lower rates of intravenous drug use. ${ }^{19-22}$ Of patients entering OST in a primary care setting, $81 \%$ own their own home or apartment, ${ }^{21} 75-82 \%$ have at least a high school degree, ${ }^{19,22}$ and the majority of the patients (68-97\%) are Caucasian. ${ }^{19-27}$ This type of patient would not typically seek treatment at 
a specialized treatment center and does not take the opportunity to receive help for their addiction unless a primary care provider is willing to help them.

The type of opioid being abused does not determine if a patient chooses to have therapy in a primary care clinic. Some patients mostly abuse heroin, ${ }^{19,20}$ whereas others primarily abuse prescription opioids. ${ }^{21}$ The number of patients admitted for OST because of prescription opioid abuse (POA) is increasing28; in 2006, POA admissions were as high as $50 \%$ of all patients seeking treatment ${ }^{23}$ and the escalating OST demand surpasses the supply of specialized treatment centers. ${ }^{10,29}$

Increased demand has triggered researchers to take notice of the POA population and several studies compare how POA users are different from heroin users. There are conflicting or insignificant differences in race, age, gender, or income type demographic criteria. ${ }^{23-27}$ Note that a large study of 2,308 patients who entered treatment in Washington State, did find that POA are more likely than heroin users to be married ( $32.7 \%$ versus $20.5 \%$ ), have children (45\% versus $12.7 \%)$, and live in stable housing $(94.8 \%$ versus $77 \%) .{ }^{25}$ POA users are more likely to have earned a high school degree than heroin users, ${ }^{25-27}$ are much less likely to abuse opiates intravenously, ${ }^{23-27}$ might have an acute or chronic pain history, ${ }^{24,27}$ have a history of other psychological problems requiring treatment, ${ }^{24-26}$ and are more likely to abuse other drugs such as sedatives and antidepressants. ${ }^{24-27}$ Despite these co-morbidities, POAs have a lower opiate severity index, which makes them more likely to benefit from $\mathrm{OST}^{23}$ and are particularly well suited for treatment in a primary care setting.

\section{Effectiveness of OST in Primary Care}

Twelve studies identified the effectiveness of OST in a primary care setting. They ranged from 20 to 360 subjects. Four were retrospective descriptive studies, five were randomized controlled or experimental studies, and three were observational cohort studies. Eleven of the studies were all done in single treatment centers with convenience sampling and eight had sample sizes of less than 100 subjects so generality is limited. This is the nature of these types of studies. 
The safety and effectiveness of buprenorphine in primary care is well established. ${ }^{14,15}$ A landmark study testing the safety and effectiveness of buprenorphine/naloxone treatment in an outpatient setting found:

Direct and rapid induction onto buprenorphine-naloxone was safe and well tolerated...Medication compliance and treatment engagement was high... The safety profile of buprenorphine-naloxone was excellent...All providers successfully integrated buprenorphine-naloxone into their existing treatment milieus. Overall, data from the CTN (NIDA's National Drug Abuse Treatment Clinical Trials Network) field experience suggest that buprenorphine-naloxone is practical and safe for use in diverse community treatment settings, including those with minimal experience providing opioid-based pharmacotherapy and/or medical detoxification for opioid dependence. ${ }^{30}(\mathrm{pS} 43)$

POA patients are significantly more likely to complete treatment than heroin only patients. ${ }^{33}$ They have higher opioid negative urine screens and achieved longer duration of continuous opioid abstinence. ${ }^{21,33}$ Torrington (2007) reported improvement in $80 \%$ of POA users verses $46 \%$ improvement in the heroin users in a primary care setting. ${ }^{27}$ Moore (2007) found the dropout rates for heroin users were $24 \%$, combined users were $2 \%$, and POA only users had a $0 \%$ dropout rate when treated in a primary care setting. ${ }^{31}$

It is important to note that heroin users are successfully treated in primary care setting as well, just not to the same degree as POA users. $20,21,24,27,32-35$ Heroin users' treatment outcomes in the primary care setting are comparable to opioid treatment programs (OTP) in secondary centers, which usually use methadone. ${ }^{19,31}$ Retention rates after 1-2 years of buprenorphine therapy are 40-68\% regardless of the type of opioid being abused. ${ }^{21,35,35}$ Buprenorphine is significantly more effective in both the POA and heroin abuse populations, with retention rates of $87.5 \%$ and $60 \%$ respectively, than it was for patients on clonidine therapy, with retention rates of $44.4 \%$ and $33.3 \%$ and twice the number of drug-free urine tests for both populations doing buprenorphine therapy. ${ }^{36}$ Lucas (2010) found primary care clinic patients started therapy faster, remained in treatment longer, and had fewer opiate positive drug screens than the patients randomized to an OTP. ${ }^{33}$ We can conclude that both heroin and POA populations are well suited for OST in a primary care practice setting. POA users might have better success rate due the fact that they often come from a more stable home environment and their addiction might not be as severe. 
The key for deciding whether a provider should prescribe buprenorphine therapy or methadone therapy may be determined by the individual's degree of addiction rather than the drug being abused. Although high dose buprenorphine therapy has shown to be more effective than low dose methadone therapy, it is not as effective as high dose methadone therapy in the severely addicted patient. ${ }^{3}$ When patients have used high doses of opiates for a long period of time, buprenorphine's partial activation of the mu receptors sites may not be enough to overcome withdrawal symptoms. Methadone activates the receptor sites fully which may account for why severely addicted patients have higher retention rates and longer periods of abstinence on this drug. ${ }^{3}$ Primary care providers may want to consider referring severely addicted patients to OTPs and treating patients in their office who have had a shorter intensity and duration of addiction.

Unfortunately, opiate addiction is a long term illness and relapse is common. Patients who wean off the OST frequently cannot sustain abstinence. Studies show that opioid related deaths are lowest while they are on OST therapy but rise substantially during the first year after treatment has been discontinued. ${ }^{3}$ These rates are the same for both MMT and buprenorphine therapy.

\section{Patient Satisfaction}

Four studies were identified that explored patient satisfaction with care in a primary care setting. They ranged from 29 to 142 subjects. Two were observational cohort studies, one had qualitative study interviews of patients in a randomized clinical trial and the other was a randomized clinical trial. Assessments are largely subjective in studies like these and each study had generalizability challenges depending on the size or population targeted in the study.

Patients express high satisfaction with buprenorphine therapy from a primary care setting. ${ }^{22,34,35}$ Patients prefer primary care therapy over OTPs because they believe the practitioner is more helpful in dealing with their problem, the buprenorphine/naloxone medication is more effective than MMT, they are treated more like a patient than an addict, the treatment is very helpful, and they like the staff's experience and concern for 
them. ${ }^{22}$ In an in-depth qualitative study, patients were randomized to a general practice or an OTP. There was an overwhelming preference for the general practice. ${ }^{35}$ Three-fourths of the patients randomized to the OTP ended up transferring to the general practice, yet none of the 16 patients randomized to the general practice transferred to the OTP. Most patients who had prior MMT in an OTP would not go back to it and preferred the general practice. In the general practice they felt like there was greater convenience with better overall care; more respect, trust, and empathy from providers; increased autonomy, shared power, and responsibility; and they were able to distance themselves from the drug scene, giving them a better environment for sobriety and relapse prevention. ${ }^{35}$ In all the studies, patients preferred being treated for their opioid addiction with their primary care providers rather than going to a specialty clinic.

\section{Barriers for OST Treatment in Primary Care}

Six studies identified physician perceived barriers of providing OST in a primary care setting. They ranged from 27 to 545 physicians surveyed. They were all descriptive survey studies but some asked open ended questions while others were to mark multiple choice answers. The studies targeted different types of providers, in limited areas of the country, and some had low return rates, therefore limiting generalizability.

The slow adoption of OST in primary care has influenced many researchers to investigate the barriers preventing providers from offering this service and offer recommendations to reduce the treatment gap. Table 2Barriers for OST by Physicians, lists the detailed barriers each study evaluated and how strongly physicians felt this was a barrier to them in prescribing OST in their personal practice. Not all of the barriers were identified in every study and most of them compared providers who are prescribing OST to providers who are not prescribing OST. In general, the physicians not waivered or not currently prescribing OST rated barriers higher than physicians who were actively engaged in OST. Netherland (2009) states, "most factors that affect willingness to prescribe buprenorphine are less significant for experienced prescribers than they are for physicians new to buprenorphine treatment, suggesting that experience eases — at least in part—a number of 
concerns". ${ }^{17}(\mathrm{p} 249)$ This lack of experience or training for physicians was one of the most significant barriers identified. ${ }^{10,11,17,19,29}$ There is limited attention given to teaching addiction medicine in medical school. ${ }^{13}$ On the other hand, after completing the waiver course for buprenorphine, most physicians reported that they felt prepared to prescribe buprenorphine, but would feel more comfortable if they had access to an expert mentor. ${ }^{19}$ Consequently, limited access to mentor/expert or substance abuse counseling/mental health services is identified as another significant barrier. ${ }^{10,13,17,19,29}$

Inadequate reimbursement is another barrier consistently listed by physicians; however, in most studies it was not as significant as the lack of education. ${ }^{10,11,17,19,29}$ This is one of the few barriers ranked higher by prescribing physicians than those not prescribing. ${ }^{17,37}$ One study mentioned that having financial incentives for training and reimbursement would draw more physicians into the practice. ${ }^{10}$ Expanding Medicare addiction treatment coverage, as well as private insurance, would reduce that barrier. ${ }^{10,17}$ Most patients who present for this service are self-pay and research has shown that patients have higher retention rates if they have a source of payment from insurance or a willing family member. ${ }^{32}$ Then again, many patients enter treatment because the cost of treatment, $\$ 300-\$ 500 /$ month in 2005 dollars, ${ }^{32}$ is less than the cost of obtaining the drugs illicitly, $\$ 800-\$ 1200 /$ month in 2006 dollars. ${ }^{23}$

Administrative type barriers such as extra training, obtaining DEA waivers, record keeping requirements, having access to buprenorphine or methadone medications, storage of the medications in their office, and/or access to pharmacies that will dispense these drugs were also concerns for physicians. ${ }^{10,11,13,17,19}$ Researchers also found a need for more access to nursing assistance with this process ${ }^{11,19}$ and mentioned the need to hire an NP to follow and manage these patients to make treatment cost effective. ${ }^{10}$ Some physicians believe these patients will require a longer time to treat ${ }^{10,17}$ and their office is not set up to meet their treatment needs. 
The stigma of opioid dependent patients or concerns of compliance and diversion are mentioned in several studies. 10,11,13,17,19,29 The patients are labeled as difficult, demanding, time consuming, complaining, and manipulative. Physicians worry that caring for this type of patient will bring a "street culture" into their clinic. ${ }^{10}$ However, one recent study researched that barrier and found that most patients (12.1\%) are unaware of the OST prescribing status of the practice. Some (15.9\%) would be likely to change practices if they did offer OST but more would be likely to change due to other inconveniences like being kept waiting more that 30 minutes (28.7\%) or having a $\$ 10$ increase in fees $(26.6 \%) .{ }^{38}$ Some did not report this stigma specifically, but were worried about lack of compliance, concern about diversion, ${ }^{17,19,29}$ and a lack of interest among patients to be treated for their opioid addiction. ${ }^{11,13,17}$

The 30 patients per practice limit was a significant barrier prior to 2007. ${ }^{39}$ Current legislation allows each physician in a practice to care for 30 patients during the first year and then increase to 100 patients when the physician registers his intent to treat more. ${ }^{39}$ This legislation has helped ease the treatment gap, but more legislation is required if we are to truly overcome the barriers identified in the research.

\section{Discussion}

The population best served by office-based OST is current patients of primary care practices. They are the patients who have become addicted to opiates through past injuries, chronic pain, or poor choices. Many primary care providers are inadvertently treating their patient's addiction with monthly opioid prescriptions for their patient's pain or other symptoms. These opioids are easily diverted by the patients and can be sold to buy stronger opioids as their addiction spirals out of control. OST, in the primary care setting, gives providers an option to help their patients with their addiction using a drug that is safer and harder to divert than traditional opioids and in a treatment environment patients prefer. OST has been proven to be safe and effective in the primary care setting and many opioid addicts are more willing to undergo treatment in a primary setting than an 
OTP. Health care providers now face overcoming the barriers that block this therapy from reaching those who need it most.

"The goal of office-based treatment of opiate dependence is to improve access and reduce unmet demand by bringing more people into treatment". ${ }^{40}(\mathrm{p} 915)$ Research shows this goal is not met with our current system. "Evaluations should be performed by policy-makers at regular intervals as an integral part of the policymaking cycle, but they should also be performed by outside evaluators in order to ensure accountability and capture shortcomings". ${ }^{41}(\mathrm{p} 221)$ It is time to identify where we can make changes to improve our current system and meet the needs of Americans better.

NPs have been providing excellent primary care for several decades and many studies show that health care outcomes for patients treated by NPs are comparable to care provided by physicians. ${ }^{42,43}$ They provide safe, quality, and cost effective care. ${ }^{4}$ In fact, NPs received higher patient satisfaction scores and usually provide more health advice when compared to physicians. ${ }^{43,44}$ The Pearson Report (2009) found that NPs had less malpractice and adverse actions and fewer convictions in comparison to both MDs and DOs. ${ }^{41}$ Regulatory barriers currently prevent NPs from handling the prescription-writing portion of opioid dependence treatment. Although the Center for Substance Abuse Treatment-Substance Abuse and Mental Health Services Administration (CSAT-SAMHSA) recommended in 2008 that future training initiatives and mentoring should be expanded to other health care professional such as NPs, PAs, RNs, counselors, and certified nurse midwives, they did not specifically mention that the prescriptive authority of NPs should be expanded. ${ }^{41,43}$ Conversely, in September 2011, the Association of Nurses in AIDS Care issued a position statement calling for extending prescriptive authority to APNs:

Qualified APNs should be allowed to prescribe buprenorphine for the treatment of opioid dependence; the DATA of 2000 should be amended to allow qualified APNs to prescribe buprenorphine; and granting prescriptive privileges for buprenorphine to APNs will increase patient access to substance use treatment. ${ }^{44}$ (p92) 
If this barrier were removed NPs could serve opioid addiction populations in areas where there are physician shortages or where physicians are choosing not to treat this population. ${ }^{41}$ Schackman et al. (2006) have recognized the necessity of involving NPs in this prescriptive authority and state:

A policy research agenda for integrating buprenorphine into HIV primary care needs to address evidence gaps in rationales that support some regulatory restrictions. In particular...the prohibition of the prescription of buprenorphine by appropriately trained mid-level practitioner, such as physician assistants and nurse practitioners, should be examined. ${ }^{18}(\mathrm{pS} 252)$

Extending prescriptive authority for buprenorphine and allowing non-physician providers to become waivered, will help to decrease the treatment gap in OST. ${ }^{4}$ Roose et al. (2008) found that non-physicians (48.7\%) were more likely to express interest in prescribing buprenorphine therapy than their physician counterparts, generalist physicians (39\%), or infectious disease specialists (27.2\%). ${ }^{45}$ Many NPs are the sole health care providers in underserved communities within states where they can practice independently, serving vulnerable populations that do not have access to physicians. ${ }^{43}$ Americans in these areas go without the lifesaving service of OST simply because NPs are prohibited from providing this service. ${ }^{18} \mathrm{In}$ areas where there is access to physicians, the NPs and MDs can collaborate, support each other, and share resources, thereby reducing many of the barriers holding back primary care providers from offering this service to their patients. ${ }^{43}$ NP's can help move this agenda by encouraging their professional organizations to join the Association of Nurses in AIDS Care by creating position statements and start lobbying for legislation that would expand prescription privileges to non-physician providers for OST. They can write letters to their legislators and educate them about the necessity of this reform. They can also attend OST trainings and become better educated with the options their patients have to treat this chronic and potentially deadly illness. This would reduce the treatment gap and give most Americans who want and need this service access to OST. 


\section{Conclusion}

Most NPs deal with POA in their primary care practices. Rather than writing monthly prescriptions for their patients with opioid dependence, NPs need to have the legal authority to identify their patients with opioid addiction and inform them that they can help them get the problem under control. "Opioid-dependent individuals need access to buprenorphine therapy and prohibition of prescribing by non-physicians restricts their access to potentially life-saving treatment". ${ }^{41}(\mathrm{p} 224)$ NPs want the legal authority to help overcome these barriers, improve access, improve cost effectiveness, and reduce the "treatment gap" for people suffering from opiate addiction.

Table 1- Demographics of Patients Entering OST at Primary Care Clinics

\begin{tabular}{|c|c|c|c|c|}
\hline & $\begin{array}{c}\text { Magura } \\
2007 \\
\# 19 \\
\mathrm{~N}=86\end{array}$ & $\begin{array}{c}\text { Barry, } \\
2007 \\
\# 37 \\
N=142\end{array}$ & $\begin{array}{c}\text { Sullivan, } \\
2005 \\
\# 34 \quad \mathrm{~N}=96\end{array}$ & $\begin{array}{c}\text { Soeffing, } \\
2009 \\
\# 4 \quad \mathrm{~N}=255\end{array}$ \\
\hline Age-median & 38 & 35.8 & 38 & 39.6 \\
\hline Male & $74 \%$ & $80 \%$ & $77 \%$ & $56.5 \%$ \\
\hline Caucasian & $82 \%$ & $76.8 \%$ & $68 \%$ & \\
\hline $\begin{array}{c}\text { Full time } \\
\text { employment }\end{array}$ & $58 \%$ & $85 \%$ & $46 \%$ & $45 \%$ \\
\hline Home Owner & $81 \%$ & & & \\
\hline$>$ HS education & & $81.7 \%$ & $75 \%$ & \\
\hline Years of opioid use & 6.7 & 7.8 & 10 & \\
\hline Prior treatment & $59 \%$ & $64.8 \%$ & $46 \%$ & $25.9 \%$ \\
\hline \multicolumn{5}{|l|}{ Type of Drug use } \\
\hline Heroin & $38 \%$ & $28.8 \%$ & $94 \%$ & $83 \%$ \\
\hline Prescription Drugs & $62 \%$ & $17.6 \%$ & & $28.2 \%$ \\
\hline Combination & & $53.6 \%$ & $6 \%$ & \\
\hline
\end{tabular}


Table 2- Perceived Barriers for OST by Physicians

\begin{tabular}{|c|c|c|c|c|c|c|c|c|c|c|c|c|}
\hline \multirow[b]{2}{*}{ Perceived Barriers identified } & \multicolumn{3}{|c|}{$\begin{array}{c}\text { Netherland } 2009 \mathrm{n}=172 \\
\text { 1=doesn't affect at all } \\
\text { 5= strongly affects * }\end{array}$} & \multicolumn{2}{|c|}{$\begin{array}{l}\text { Kissin } 2006 \mathrm{n}=545 \\
\text { Detox= detoxification } \\
\text { Maint= maintenance }{ }^{* *}\end{array}$} & \multirow{2}{*}{ 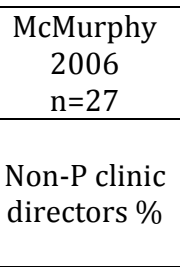 } & \multicolumn{2}{|c|}{$\begin{array}{c}\text { Sullivan } 2006 \\
n=257\end{array}$} & \multicolumn{2}{|c|}{$\begin{array}{c}\text { Cunningham } 2007 \\
\mathrm{n}=375\end{array}$} & \multicolumn{2}{|c|}{$\begin{array}{c}\text { Walley } 2008 \\
n=235\end{array}$} \\
\hline & $\begin{array}{c}\text { Expert } \\
\text { P } \\
n=78\end{array}$ & $\begin{array}{c}\text { Novice } \\
\mathrm{P} \\
\mathrm{n}=45\end{array}$ & $\begin{array}{c}\text { Non-P } \\
n=49\end{array}$ & $\begin{array}{c}\mathrm{P} \% \\
\text { Detox/Maint } \\
\mathrm{n}=241 / 218\end{array}$ & $\begin{array}{c}\text { Non-P \% } \\
\text { Detox/ Maint } \\
n=60 / 58\end{array}$ & & $\begin{array}{c}\text { \% HIV } \\
\text { MD } \\
n=112\end{array}$ & $\begin{array}{c}\text { \%Non } \\
\text {-HIV } \\
\text { MD } \\
n=144\end{array}$ & $\begin{array}{c}\% \text { with } \\
\text { waiver } \\
n=94\end{array}$ & $\begin{array}{c}\% \text { No } \\
\text { waiver } \\
n=281\end{array}$ & $\begin{array}{c}\mathrm{P} \% \\
\mathrm{n}=156\end{array}$ & $\begin{array}{c}\text { Non-P } \\
\% \\
n=79\end{array}$ \\
\hline Stigma- being a difficult patient & & & & & & $93 \%$ & & & $36.3 \%$ & $45.4 \%$ & $7 \%$ & $0 \%$ \\
\hline Lack of training for clinic staff & 3.1 & 3.4 & 3.9 & & & $26 \%$ & & & & & $7 \%$ & $22 \%$ \\
\hline Access to sub-abuse counseling & 3.1 & 3.7 & 3.9 & \multirow[t]{2}{*}{$9.5 \% / 16.1 \%$} & \multirow[t]{2}{*}{$8.3 \% / 12.1 \%$} & $44 \%$ & & & & & & \\
\hline Access to mental health service & 3.0 & 3.8 & 3.7 & & & & & & & & & \\
\hline Longer time for pt visit & 3.3 & 3.4 & 3.6 & & & $56 \%$ & & & & & & \\
\hline Availability of BUP/ methadone & 3.2 & 3.5 & 3.8 & $27.4 \% / 29.8 \%$ & $25.0 \% / 25.9 \%$ & $26 \%$ & & & & & $12 \%$ & $1 \%$ \\
\hline $\begin{array}{l}\text { Effective referral system for } \\
\text { alternate drug treatment }\end{array}$ & 3.0 & 3.1 & 3.8 & & & & & & $34.8 \%$ & $48.1 \%$ & & \\
\hline Chronic pain treatment & 3.0 & 3.5 & 3.8 & & & & & & & & & \\
\hline No clinical guidelines available & 2.5 & 3.1 & 3.7 & & & & & & & & & \\
\hline Inadequate reimbursement & 3.5 & 2.8 & 2.7 & & & $26 \%$ & $9 \%$ & $15 \%$ & $24.2 \%$ & $31.5 \%$ & $21 \%$ & $10 \%$ \\
\hline Record keeping requirements & 2.3 & 2.8 & 3.0 & $14.9 \% / 15.1 \%$ & $25.0 \% / 25.9 \%$ & $26 \%$ & $9 \%$ & $15 \%$ & & & & \\
\hline Access to consult with expert & 2.0 & 2.8 & 3.0 & & & & $78 \%$ & $82 \%$ & $15.6 \%$ & $23.1 \%$ & & \\
\hline Extra training and DEA waiver & 2.0 & 2.2 & 2.6 & $18.3 \% / 22.9 \%$ & $30.0 \% / 37.9 \%$ & $26 \%$ & $9 \%$ & $15 \%$ & & & & \\
\hline $\begin{array}{l}\text { Outside scope of expertise or lack } \\
\text { of addiction experience MD }\end{array}$ & 1.8 & 2.1 & 2.6 & & & $44 \%$ & $9 \%$ & $15 \%$ & $44 \%$ & $63.8 \%$ & $3 \%$ & $3 \%$ \\
\hline Difficult inductions logistics & 1.7 & 2.4 & 2.7 & $31.1 \% / 23.8 \%$ & $25.0 \% / 25.9 \%$ & & & & & & & \\
\hline Concern about diversion & 2.0 & 2.2 & 2.5 & & & & $9 \%$ & $15 \%$ & $40.4 \%$ & $44.4 \%$ & & \\
\hline Lack of interest among patients & 1.7 & 2.1 & 2.5 & $11.2 \% / 13.8 \%$ & $11.7 \% / 12.1 \%$ & & & & & & $2 \%$ & $18 \%$ \\
\hline Lack of patient compliance & & & & $13.7 \% / 21.1 \%$ & $23.3 \% / 31.0 \%$ & & $8 \%$ & & $26.1 \%$ & $34.7 \%$ & & \\
\hline Lack of interest among provider & 1.9 & 1.8 & 2.2 & & & & & & $26.7 \%$ & $31.5 \%$ & $13 \%$ & $30 \%$ \\
\hline Prefer alternate treatment & 1.6 & 1.8 & 2.1 & & & & & & & & & \\
\hline Effectiveness not demonstrated & 1.3 & 1.4 & 1.8 & & & & & & & & & \\
\hline Patient side effects & & & & $7.9 \% / 5.5 \%$ & $6.7 \% / 5.2 \%$ & & $46 \%$ & & & & & \\
\hline Bringing street culture to office & & & & & & $48 \%$ & & & & & & \\
\hline Need more nurses or NP support & & & & & & $44 \%$ & $8 \%$ & & & & $16 \%$ & $27 \%$ \\
\hline Time and \$ for MD training & & & & & & $26 \%$ & & & & & & \\
\hline Increased legal risks & & & & & & & & & $28.9 \%$ & $46.4 \%$ & & \\
\hline Lack of institutional support & & & & & & & & & & & $12 \%$ & $24 \%$ \\
\hline
\end{tabular}

$\mathrm{n}=$ number of MD's surveyed $\quad \mathrm{P}=$ MD's who currently prescribe OST

Non-P=MD's who do not prescribe OST or have stopped prescribing it

*Netherland used a 1-5 Likert scale with 1 (doesn't effect at all) to 5 (strongly affects)

**Kissin compared MD's who did detoxification (Detox) from opioids only to those who prescribed long term maintenance therapy (Maint) 


\section{References}

1. Zacny J, Bigelow G, Compton P, Foley K, Iguchi M, Sannerud C. College on problems of drug dependence taskforce on prescription opioid non-medical use and abuse: Position statement. DRUG ALCOHOL DEPENDENCE. 2003;69(3):215-232. 2. Mendelson J, Flower K, Pletcher MJ, Galloway GP. Addiction to prescription opioids: Characteristics of the emerging epidemic and treatment with buprenorphine. Exp Clin Psychopharmacol. 2008;16(5):435-441.

3. Bonhomme J, Shim RS, Gooden R, Tyus D, Rust G. Opioid addiction and abuse in primary care practice: a comparison of methadone and buprenorphine as treatment options. Journalof the National Medical Association. 2012;104(7-8):342-350.

4. Kvamme E, Catlin M, Banta-Green C, Roll J, Rosenblatt R. Who prescribes buprenorphine for rural patients? The impact of specialty, location and practice type in washington state. Journal of Substance Abuse Treatment. 2013;44:355-360

5. Substance Abuse and Mental Health Services Administration. National survey on drug use and health: Detailed tables. . 2010: quick tables. http://www.icpsr.umich.edu/quicktables/quickconfig.do?32722-0001_all. Accesses June 4, 2012.

6. Ward J, Hall W, Mattick RP. Role of maintenance treatment in opioid dependence. Lancet. 1999;353(9148):221-226.

7. Nicholls L, Bragaw L, Ruetsch C. Opioid dependence treatment and guidelines. J Manag Care Pharm. 2010;16(1):S14-S21.

8. Substance Abuse and Mental Health Services Administration. Results from the 2008 national survey of drug use and health: National findings. http://www.samhsa.gov/data/nsduh/2k8nsduh/2k8results.pdf. Accessed August 1, 2012.

9. Strassels SA. Economic burden of prescription opioid misuse and abuse. J Manag Care Pharm. 2009;15(7):556-562.

10. McMurphy S, Shea J, Switzer J, Turner BJ. Clinic-based treatment for opioid dependence: A qualitative inquiry. Am J Health Behav. 2006;30(5):544-554.

11. Walley AY, Alperen JK, Cheng DM, et al. Office-based management of opioid dependence with buprenorphine: Clinical practices and barriers. J Gen Intern Med. 2008;23(9):1393-1398.

12. Drug addiction treatment act of 2000. CSAT buprenorphine information center Web site. http://buprenorphine.samhsa.gov/data.html. Updated 2010. Accessed August 1, 2012.

13. Kissin W, McLeod C, Sonnefeld J, Stanton A. Experiences of a national sample of qualified addiction specialists who have and have not prescribed buprenorphine for opioid dependence. Journal of Addictive Diseases. 2006;25(4):91-103.

14. Kahan M, Srivastava A, Ordean A, Cirone S. Buprenorphine: New treatment of opioid addiction in primary care. Can Fam Physician. 2011;57(3):281-289. 
15. Ducharme S, Fraser R, Gill K. Update on the clinical use of buprenorphine: In opioid-related disorders. Can Fam Physician. 2012;58(1):37-41.

16. Caldiero RM, Parran,Theodore V.,,Jr, Adelman CL, Piche B. Inpatient initiation of buprenorphine maintenance vs. detoxification: Can retention of opioid-dependent patients in outpatient counseling be improved? Am J Addict. 2006;15(1):1-7.

17. Netherland J, Botsko M, Egan JE, et al. Factors affecting willingness to provide buprenorphine treatment. J Subst Abuse Treat. 2009;36(3):244-251.

18. Burda-Cohee C. Buprenorphine products for the pharmacologic management of opioid addiction: Why shouldn't advanced practice nurses prescribe? J ADDICT NURS. 2006;17(2):139-145.

19. Sullivan LE, Chawarski M, O'Connor P, Schottenfeld RS, Fiellin DA. The practice of office-based buprenorphine treatment of opioid dependence: Is it associated with new patients entering into treatment? DRUG ALCOHOL DEPENDENCE. 2005;79(1):113116.

20. Soeffing JM, Martin LD, Fingerhood MI, Jasinski DR, Rastegar DA. Buprenorphine maintenance treatment in a primary care setting: Outcomes at 1 year. $J$ Subst Abuse Treat. 2009;37(4):426-430.

21. Magura S, Lee SJ, Salsitz EA, et al. Outcomes of buprenorphine maintenance in office-based practice. Journal of Addictive Diseases. 2007;26(2):13-23.

22. Barry DT, Moore BA, Pantalon MV, et al. Patient satisfaction with primary care office-based buprenorphine/naloxone treatment. $J$ Gen Intern Med. 2007;22(2):242-245.

23. Sigmon SC. Characterizing the emerging population of prescription opioid abusers. Am J Addict. 2006;15(3):208-212.

24. Brands B, Blake J, Sproule B, Gourlay D, Busto U. Prescription opioid abuse in patients presenting for methadone maintenance treatment. DRUG ALCOHOL DEPENDENCE. 2004;73(2):199-207.

25. Banta-Green C, Maynard C, Koepsell TD, Wells EA, Donovan DM. Retention in methadone maintenance drug treatment for prescription-type opioid primary users compared to heroin users. Addiction. 2009;104(5):775-783.

26. Subramaniam GA, Stitzer MA. Clinical characteristics of treatment-seeking prescription opioid vs. heroin-using adolescents with opioid use disorder. DRUG ALCOHOL DEPENDENCE. 2009;101(1-2):13-19.

27. Torrington M, Domier CP, Hillhouse M, Ling W. Buprenorphine 101: Treating opioid dependence with buprenorphine in an office-based setting. Journal of Addictive Diseases. 2007;26(3):93-99.

28. Sander SCE, Hays LR. Prescription opioid dependence and treatment with methadone in pregnancy. J Opioid Manag. 2005;1(2):91-97. 
29. Cunningham CO, Kunins HV, Roose RJ, Elam RT, Sohler NL. Barriers to obtaining waivers to prescribe buprenorphine for opioid addiction treatment among HIV physicians. J Gen Intern Med. 2007;22(9):1325-1329.

30. Amass L, Ling W, Freese TE, et al. Bringing buprenorphine-naloxone detoxification to community treatment providers: The NIDA clinical trials network field experience. Am J Addict. 2004;13 Suppl 1:42-S66.

31. Moore BA, Fiellin DA, Barry DT, et al. Primary care office-based buprenorphine treatment: Comparison of heroin and prescription opioid dependent patients. Journal of General Internal Medicine. 2007;22(4):527-530.

32. Colameco S, Armando J, Trotz C. Opiate dependence treatment with buprenorphine: One year's experience in a family practice residency setting. J Addict Dis. 2005;24(2):25-32.

33. Lucas GM, Chaudhry A, Hsu J, et al. Clinic-based treatment of opioid-dependent HIV-infected patients versus referral to an opioid treatment program. Annals of Internal Medicine. 2010;152(11):704-712.

34. Fiellin DA, Moore BA, Sullivan LE, et al. Long-term treatment with buprenorphine/naloxone in primary care: Results at 2-5 years. Am J Addict. 2008;17(2):116-120.

35. Korthuis PT, Gregg J, Rogers WE, McCarty D, Nicolaidis C, Boverman J. Patients' reasons for choosing office-based buprenorphine: Preference for patient-centered care. Journal of Addiction Medicine. 2010;4(4):204-210.

36. Motamed M, Marsch LA, Solhkhah R, Bickel WK, Badger GJ. Differences in treatment outcomes between prescription opioiddependent and heroin-dependent adolescents. Journal of Addiction Medicine. 2008;2(3):158-164.

37. Gunderson EW, Wang X, Fiellin DA, Bryan B, Levin FR. Unobserved versus observed office buprenorphine/naloxone induction: A pilot randomized clinical trial. Addict Behav. 2010;35(5):537-540.

38. Holliday SM, Magin PJ, Dunbabin JS, Ewald BD, Henry JM, Goode SM, Baker FA, Dunlop AJ. Waiting room ambience and provision of opioid substitution therapy in general practice. The Medical Journal of Australia. 2012;196(6):391-394.

39. Arfken CL, Johanson C, di Menza S, Schuster CR. Expanding treatment capacity for opioid dependence with office-based treatment with buprenorphine: National surveys of physicians. J Subst Abuse Treat. 2010;39(2):96-104.

40. Thomas CP, Reif S, Haq S, Wallack SS, Hoyt A, Ritter GA. Use of buprenorphine for addiction treatment: Perspectives of addiction specialists and general psychiatrists. Psychiatr Serv. 2008;59(8):909-916.

41. Fornili K, Burda C. Buprenorphine prescribing: Why physicians aren't and nurse prescribers can't. Journal of Addictions Nursing. 2009;20(4):218-226.

42. Fornili K. Another quality chasm: The failure of nursing to clearly communicate its role within the addiction treatment workforce. J ADDICT NURS. 2007;18(1):57-59. 
43. O’Connor AB. Nurse practitioners' inability to prescribe buprenorphine: Limitations of the drug addiction treatment act of 2000. $J$ Am Acad Nurse Pract. 2011;23(10):542-545.

44. Advanced practice nurse prescriptive authority of buprenorphine: Adopted by the ANAC board of directors september 17, 2011. $J$ Assoc Nurses AIDS Care. 2012;23(1):92-93.

45. Roose RJ, Kunins HV, Sohler NL, Elam RT, Cunningham CO. Nurse practitioner and physician assistant interest in prescribing buprenorphine. J Subst Abuse Treat. 2008;34(4):456-459. 